\title{
Micromonas micros Infection of a Prosthetic Hip Joint: A Case Report and Review of the Literature
}

\author{
Abhimanyu Aggarwal (D) and Durane Walker (D) \\ Division of Infectious Diseases, Department of Medicine, University of Massachusetts Medical School, Baystate Medical Center, \\ Springfield, MA, USA
}

Correspondence should be addressed to Abhimanyu Aggarwal; abhi.aggarwal@outlook.com

Received 28 June 2021; Accepted 6 September 2021; Published 20 September 2021

Academic Editor: Larry M. Bush

Copyright (c) 2021 Abhimanyu Aggarwal and Durane Walker. This is an open access article distributed under the Creative Commons Attribution License, which permits unrestricted use, distribution, and reproduction in any medium, provided the original work is properly cited.

\begin{abstract}
Micromonas micros is an oral anaerobic Gram-positive coccus and is a commensal of the mouth, and it is rarely isolated in prosthetic joint infections (PJIs) and even less frequently related to a preceding dental procedure with eventual hematogenous seeding of the prosthetic joint. Here, we present a case of a 56-year-old male with a prosthetic hip joint who developed Micromonas micros prosthetic hip joint infection with symptoms starting a few days after a dental procedure and not having received periprocedural antibiotic prophylaxis. He recovered well with surgical intervention and antimicrobial therapy. We conducted a literature review of prosthetic hip joint infections caused by Micromonas micros as well as briefly discuss current guidelines on antibiotic prophylaxis in patients with prosthetic joints undergoing dental procedures and some knowledge gaps.
\end{abstract}

\section{Case Description}

A 56-year-old male was admitted with four days of progressively worsening left hip pain leading to difficulty in ambulation as well as a documented fever of $100.9^{\circ} \mathrm{F}$ at home. It started immediately after he was working in the yard, and he noted a "popping sensation." His primary-care provider ordered labs which came back abnormal for leukocytosis $14,000 / \mathrm{mm}^{3}$ (predominantly neutrophilic), ESR $66 \mathrm{~mm} / \mathrm{hr}$ (reference range $0-20 \mathrm{~mm} / \mathrm{hr}$ ) and CRP $12.9 \mathrm{mg} / \mathrm{dL}$ (reference range $0-0.5 \mathrm{mg} / \mathrm{dL}$ ) which prompted the hospital referral. Three days prior to onset of symptoms, he underwent routine dental cleaning with flossing and minor bleeding during the procedure. He was not administered prophylactic antibiotics. He underwent left total hip replacement surgery 5 years prior to this admission and right total hip replacement 8 years prior to this admission, both times for severe osteoarthritis. Other relevant medical history included benign prostatic hyperplasia. He did not indulge in tobacco, alcohol, or illicit drug use. He had no antibiotic allergies.

On admission, his vital signs including temperature were normal. He had a body mass index of 28.9. Pertinent abnormality on examination included extreme difficulty in the range of motion of the left hip due to pain in all directions. Pertinent labs including hemoglobin, platelet counts, and kidney function were unremarkable. X-ray of the left hip ruled out fracture or dislocation. Blood cultures were drawn prior to administration of antibiotics which later returned negative.

He underwent interventional radiology-guided aspiration of the left hip joint on day 2 of hospitalization, with retrieval of $5 \mathrm{cc}$ of pus. Unfortunately, the specimen could not be evaluated for crystals or cell counts since it was described as too viscous. However, Gram staining demonstrated numerous neutrophils and moderate Gram-positive cocci in pairs and chains. Intravenous (IV) vancomycin (2 grams loading dose, followed by 1.5 grams every 12 hourly) and ceftriaxone 2 grams daily were started. On day 3 , he was taken to the operating room and underwent total left hip revision with liner swap and irrigation and debridement. Mild joint loosening was noted intraoperatively, and joint fluid cultures were sent.

Specimens from day 2 as well as day 3 came back positive in anaerobic cultures for Micromonas micros, susceptible to penicillin, clindamycin, and metronidazole (Figures 1-3). A 


\begin{tabular}{|c|c|c|}
\hline Date/Time & Procedure/Result & Report/Grid \\
\hline $\begin{array}{l}\text { 4/29/21 00:00 } \\
\text { Hip, Left }\end{array}$ & $\begin{array}{c}\text { Anaerobic/Aerobic Culture - Final } \\
\text { Anaerobic Gram Positive Cocci }\end{array}$ & \\
\hline $\begin{array}{c}\text { 4/29/21 00:00 } \\
\text { Hip, Left }\end{array}$ & $\begin{array}{l}\text { Tissue Culture - Final } \\
\text { Anaerobic Gram Positive Cocci }\end{array}$ & \\
\hline $\begin{array}{c}\text { 4/29/21 00:00 } \\
\text { Hip, Left }\end{array}$ & $\begin{array}{c}\text { Anaerobic/Aerobic Culture - Final } \\
\text { Anaerobic Gram Positive Cocci }\end{array}$ & \\
\hline $\begin{array}{c}\text { 4/28/21 16:03 } \\
\text { Hip, Left } \\
\text { Complete }\end{array}$ & Anaerobic Culture - Final & \\
\hline $\begin{array}{c}\text { 4/28/21 16:03 } \\
\text { Synovial Hip, Left } \\
\text { Cancelled }\end{array}$ & & \\
\hline $\begin{array}{c}\text { 4/28/21 15:43 } \\
\text { Hip, Left } \\
\text { Complete }\end{array}$ & $\begin{array}{l}\text { Anaerobic/Aerobic Culture - Final } \\
\text { Anaerobic Gram Positive Cocci }\end{array}$ & \\
\hline $\begin{array}{c}\text { 4/27/21 } 21: 10 \\
\text { Nasopharyngeal } \\
\text { Complete }\end{array}$ & SARS-CoV-2 Rapid RNA (RT-PCR) - Final & \\
\hline $\begin{array}{c}\text { 4/27/21 } 18: 15 \\
\text { Peripheral Draw } \\
\text { Complete }\end{array}$ & $\begin{array}{l}\text { Blood Culture - Final } \\
\text { NO GROWTH AFTER } 5 \text { DAYS }\end{array}$ & 8 \\
\hline $\begin{array}{c}\text { 4/27/21 } 18: 10 \\
\text { Peripheral Draw } \\
\text { Complete }\end{array}$ & $\begin{array}{l}\text { Blood Culture - Final } \\
\text { NO GROWTH AFTER } 5 \text { DAYS }\end{array}$ & $6 / 4$ \\
\hline
\end{tabular}

Figure 1: Compiled view of culture results.

diagnosis of left hip prosthetic joint infection with debridement, antibiotics, and implant retention (DAIR) was established. Vancomycin was discontinued, and he was discharged on IV ceftriaxone 2 grams daily via peripherally inserted central venous catheter line for 6 weeks for ease of dosing. Weekly follow-up labs were performed and demonstrated normalization of WBC and inflammatory markers (ESR and CRP). Overall, he clinically improved and was later transitioned to 6 weeks of oral penicillin $\mathrm{V} 1$ gram three times a day. 


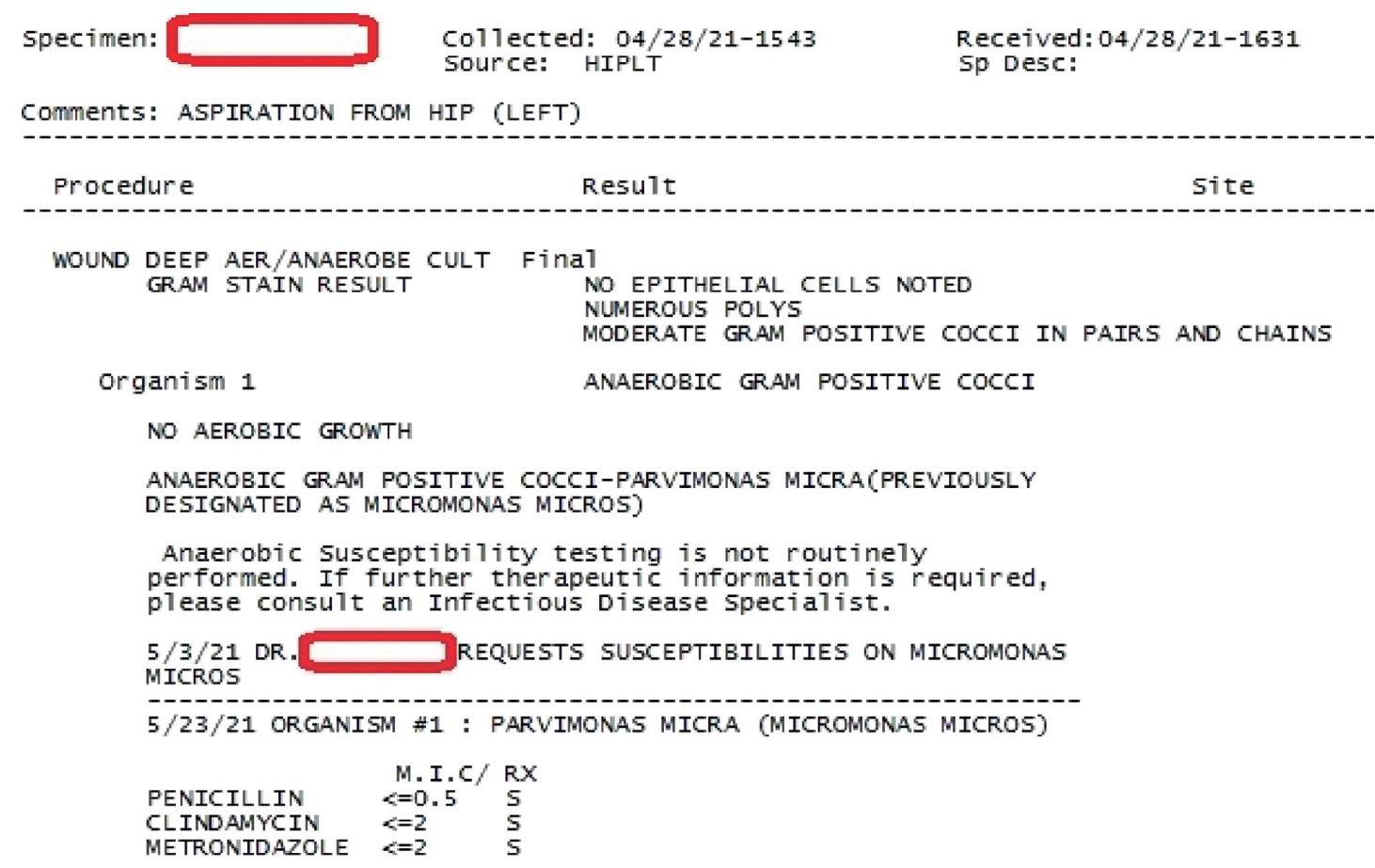

MICs are expressed in micrograms per $\mathrm{mL}$

FIGURE 2: Details of hip aspirate culture results.

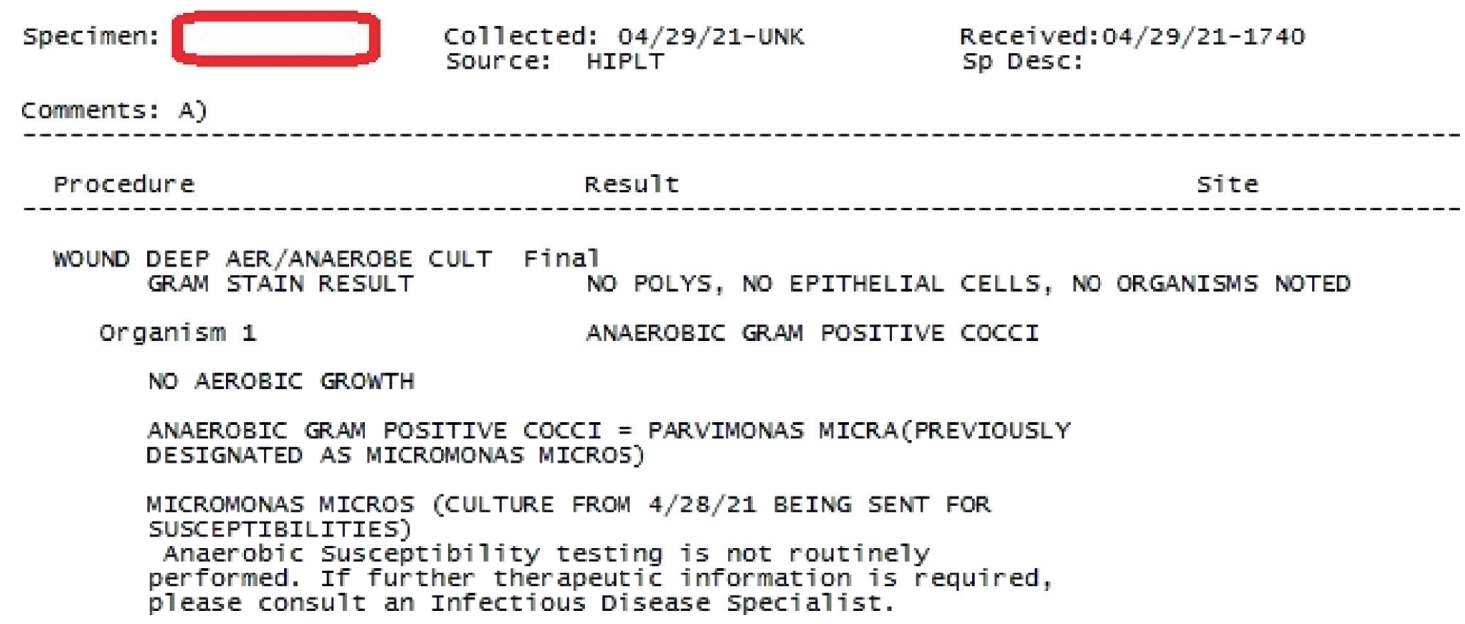

FIGURE 3: Details of intraoperative culture results.

\section{Discussion}

Micromonas micros (M. micros), which has now been renamed Parvimonas micra and previously called Peptostreptococcus micros, is an anaerobic Gram-positive coccus, usually a member of oral flora and often has been isolated from the respiratory tract and gastrointestinal tract, as well as the female genital tract $[7,8]$. Anaerobic oral microorganisms have been implicated as the causative agents for late-onset prosthetic joint infections (late in reference from the time of prosthetic joint creation) [1].

M. micros has been infrequently reported as a cause of prosthetic joint infections. Randall et al. reviewed the literature for $M$. micros prosthetic joint infection of the knee joint and included 7 cases [9]. Overall, it was noted that different authors used different antibiotics for management and reported varying time duration between initial prosthetic knee joint creation and onset of symptoms of knee PJI. Only 5 of these cases had a documented preceding dental procedure. Here, we reviewed the literature for all the reported hip joint PJI's with M. micros and found 10 reported cases with scant information about several aspects of management, as reported in Table 1. However, like our case, only the case report by Bartz et al. reported a potential association between the preceding dental procedure and isolation of M. micros in the hip PJI 
TABLE 1: Summary of reported cases of Micromonas micros PJI in the hip joint.

\begin{tabular}{|c|c|c|c|c|}
\hline Report & Age/gender & $\begin{array}{l}\text { Time interval between initial prosthetic joint } \\
\text { creation and symptom onset }\end{array}$ & Antibiotic choice; duration & Outcome \\
\hline $\begin{array}{l}\text { Petrini et al. } \\
{ }_{* * *}[1]\end{array}$ & Male* & 4 years & - & - \\
\hline Petrini et al. [1] & Male* & 3 years & - & - \\
\hline $\begin{array}{l}\text { Petrini et al. } \\
* * *[1]\end{array}$ & Male* & 3 years & - & - \\
\hline $\begin{array}{l}\text { Petrini et al. } \\
* * *[1]\end{array}$ & Male* $^{*}$ & 2 years & - & - \\
\hline $\begin{array}{l}\text { Petrini et al. } \\
* * *[1]\end{array}$ & Female* & 5 years & - & - \\
\hline Bartz et al. [2] & $\begin{array}{l}63 \text { years/ } \\
\text { female }\end{array}$ & 9 years & IV cefuroxime/gentamicin; clindamycin** & Recovered \\
\hline Bohra et al. [3] & $\begin{array}{l}67 \text { years/ } \\
\text { female }\end{array}$ & 8 months & IV vancomycin 2 weeks & Recovered \\
\hline Huang et al. [4] & $\begin{array}{l}65 \text { years/ } \\
\text { female }\end{array}$ & 7 years & $\begin{array}{l}\text { IV piperacillin/tazobactam } 2 \text { weeks; PO } \\
\text { amoxicillin/clavulanic acid } 8 \text { weeks }\end{array}$ & Recovered \\
\hline $\begin{array}{l}\text { Marmor et al. } \\
{[5]}\end{array}$ & - & - & - & - \\
\hline Rieber et al. [6] & $\begin{array}{l}78 \text { years/ } \\
\text { female }\end{array}$ & 6 months & - & - \\
\hline $\begin{array}{l}\text { Our case report, } \\
2020\end{array}$ & $\begin{array}{l}56 \text { years/ } \\
\text { male }\end{array}$ & 5 years & IV ceftriaxone 6 weeks; PO penicillin V 6 weeks & Recovered \\
\hline
\end{tabular}

All patients had surgical intervention done for the PJI, except for lack of data on Marmor et al.'s case. * Age not specified, ** duration not specified, *** M. micros isolated as a part of polymicrobial infection IV, intravenous; PO, per oral.

[2]. Another study from 2001 reported 4 cases of $P$. micros isolated in late-onset orthopedic implant infections but did not specify the site for 2 of them as well as the treatment outcome in all 4 [10].

For nearly four decades, a controversy has existed around the decision on antibiotic prophylaxis for patients undergoing dental procedures who also have prosthetic joints. Despite the existing evidence of transient bacteremia following dental procedures $[11,12]$, guidelines still advocate against the use of prophylactic antibiotic prior to proceeding with a dental procedure in patients with prosthetic joints. The American Academy of Orthopedic Surgeons, American Dental Association, and Infectious Diseases Society of America [13-15] in their guidelines attributed to lack of evidence to associate a dental procedure with a prosthetic joint infection. However, they do make an exception for patients who are immunosuppressed (for example, malignancy or diabetes mellitus) or are on immunosuppressive therapy or have a prior history of prosthetic joint infection.

An important point was raised by Moreira et al. in a systematic review of literature for antibiotic prophylaxis for patients with prosthetic joints undergoing dental procedures [16]. Studies reviewed to come to the current consensus lacked enough knowledge on the periodontal conditions of the patients included, as well as significant heterogeneity in objective definitions of periodontal diseases. To arrive at a judgement on using antibiotic prophylaxis might require assessment of periodontal health by dental surgeons at the time of their procedure and make a final decision in that moment. This just reinforces the role for the dental surgeons to ensure review of detailed past medical history including the presence of a prosthetic joint, the timing of its creation, and if there is a prior history of PJI.

There were two major reasons why we chose to share this case report with the readers. One was to share literature review of $M$. micros hip PJI. The second was to indulge in thought-provoking discussions about the consensus on the use of antibiotic prophylaxis for patients with prosthetic joints who are about to undergo dental procedures.

In conclusion, $M$. micros hip PJIs are infrequent but still should be included in the list of pathogens responsible for late-onset PJIs. The suspicion for M. micros should be higher in patients who undergo dental procedures that put them at risk of bleeding, especially if they also have concurrent periodontal disease. Additionally, the outlook towards antibiotic prophylaxis prior to dental procedures in patients with a known prosthetic joint may possibly reach a consensus if future studies include periodontal condition as a factor affecting the decision-making process. The issue with this strategy is that the dentist would have to know the condition of the teeth and gums prior to prescribing the antibiotics.

\section{Data Availability}

No data were used to support the study.

\section{Conflicts of Interest}

There were no conflicts of interest during the preparation of this manuscript. 


\section{Acknowledgments}

The authors would like to acknowledge the contribution of Bridget Gunn, a librarian, who assisted them in performing the literature search which was invaluable in the preparation of this manuscript.

\section{References}

[1] B. Petrini, T. Welin-Berger, and C. E. Nord, "Anaerobic bacteria in late infections following orthopedic surgery," Medical Microbiology and Immunology, vol. 167, no. 3, pp. 155-159, 1979.

[2] H. Bartz, C. Nonnenmacher, C. Bollmann et al., "Micromonas (peptostreptococcus) micros: unusual case of prosthetic joint infection associated with dental procedures," International Journal of Medical Microbiology, vol. 294, no. 7, pp. 465-470, 2005.

[3] M. Bohra, D. Cwian, and C. Peyton, "Delayed infection in a patient after total hip arthroplasty," Journal of Orthopaedic \& Sports Physical Therapy, vol. 48, no. 8, p. 666, 2018.

[4] Z. Huang, C. Zhang, W. Li et al., "Metagenomic next-generation sequencing contribution in identifying prosthetic joint infection due to Parvimonas micra: a case report," Journal of Bone and Joint Infection, vol. 4, no. 1, pp. 50-55, 2019.

[5] S. Marmor, Y. Kerroumi, V. Meyssonnier et al., "One-stage exchange arthroplasty for fistulizing periprosthetic joint infection of the hip: an effective strategy," Frontiers in Medicine, vol. 7, Article ID 540929, 2020.

[6] H. Rieber, A. Frontzek, M. Alefeld et al., "Sonicate fluid inoculated into blood culture bottles does not improve diagnosis of periprosthetic joint infection caused by anaerobes. a retrospective analysis," Anaerobe, vol. 62, Article ID 102152, 2020.

[7] R. Civen, H. Jousimies-Somer, M. Marina, L. Borenstein, H. Shah, and S. M. Finegold, "A retrospective review of cases of anaerobic empyema and update of bacteriology," Clinical Infectious Diseases, vol. 20, no. Suppl 2, pp. S224-S229, 1995.

[8] D. A. Murdoch, I. J. Mitchelmore, and S. Tabaqchali, "Peptostreptococcus micros in polymicrobial abscesses," The Lancet, vol. 331, no. 8585, p. 594, 1988.

[9] D. Randall, Y. Jee, A. Vanood, and D. Mayo, "Atypical presentation of periprosthetic joint infection after total knee arthroplasty due to Parvimonas micra," Arthroplasty Today, vol. 6 , no. 4, pp. 901-905, 2020.

[10] H. A. Mousa, "Infection following orthopaedic implants and bone surgery," Eastern Mediterranean Health Journal, vol. 7, no. 4-5, pp. 738-743, 2001.

[11] C. A. Bartzokas, R. Johnson, M. Jane, M. V. Martin, P. K. Pearce, and Y. Saw, "Relation between mouth and haematogenous infection in total joint replacements," $B M J$, vol. 309, no. 6953, pp. 506-508, 1994.

[12] B. J. Waldman, M. A. Mont, and D. S. Hungerford, "Total knee arthroplasty infections associated with dental procedures," Clinical Orthopaedics and Related Research, vol. 343, no. 343, pp. 164-172, 1997.

[13] D. A. Goff, J. E. Mangino, A. H. Glassman, D. Goff, P. Larsen, and R. Scheetz, "Review of guidelines for dental antibiotic prophylaxis for prevention of endocarditis and prosthetic joint infections and need for dental stewardship," Clinical Infectious Diseases, vol. 71, no. 2, pp. 455-462, 2020.

[14] T. P. Sollecito, E. Abt, P. B. Lockhart et al., "The use of prophylactic antibiotics prior to dental procedures in patients with prosthetic joints: evidence-based clinical practice guideline for dental practitioners-a report of the American dental association council on scientific affairs," The Journal of the American Dental Association, vol. 146, no. 1, pp. 11-16, 2015.

[15] American Academy of Orthopaedic Surgeons, Evidence Based Clinical Practice Guideline for the Prevention of Orthopaedic Implant Infections in Patients Undergoing Dental Procedures, American Academy of Orthopaedic Surgeons, Rosemont, IL, USA, 2012.

[16] A. I. Moreira, L. Mendes, and J. A. Pereira, "Is there scientific evidence to support antibiotic prophylaxis in patients with periodontal disease as a means to decrease the risk of prosthetic joint infections? a systematic review," International Orthopaedics, vol. 44, no. 2, pp. 231-236, 2020. 